INDO GLOBAL JOURNAL OF

PHARMACEUTICAL SCIENCES

ISSN 2249- 1023

\title{
Development of Buccal Drug Delivery System: Novel Therapy for Diabetic Patients with Hypertension
}

\author{
Pratibha Chaudhary *, Vinay Pandit \\ Laureate Institute of Pharmacy, Kathog, Distt. Kangra \\ Address for Correspondence: Pratibha Chaudhary
}

\begin{tabular}{l} 
Received: \\
01.03.2019 \\
Accepted: \\
25.03.2019 \\
Keywords \\
Diabetes \\
mellitus; \\
Antidiabetics; \\
Metabolic \\
disorders. \\
\hline
\end{tabular}

ABSTRACT: The present studies aim that development of buccal drug delivery system novel therapy for diabetic patient with hypertension. Hypertension is a major modifiable risk factor for cardiovascular morbidity and mortality in patients with diabetes. Lowering blood pressure is the main goal of treatment. A nonpharmacologic approach is recommended in all patients. If BP levels remains above the target despite nonpharmacologic treatment drug therapy should be initiated. Blockers of the rennin-angiotensin-aldosterone system (RAAS) represent the cornerstone of the antihypertensive drug arsenal; however, in most patients combination therapy is required. For many patients a combination of RAAS blocker and calcium antagonist is the combination preferred by treating physician. The buccal tablet was prepared by using Pioglitazone and Cilnidipine as a combined dosage form with other excipients such as cabopol 971 or 974, HPMC K4M, HPMC K15CPS, Sodium CMC, Glucodeoxycholate, $\beta$ cyclodextrin, lactose, magnesium stearate, ethyl cellulose, ethanol, methanol and required amount of distilled water. The prepared buccal tablet was evaluated for physical appearance, hardness, friability, disintegration, bioadhesion strength, ex vivo residence time, swelling index and in vitro dissolution studies were performed. Stability study in natural saliva indicated that optimized formulation has good stability in human saliva. It was inferred that the prepared buccal tablet combined dosage form is very useful for the treatment of diabetic patient with hypertension. (C) 2019 iGlobal Research and Publishing Foundation. All rights reserved.

Cite this article as: Chaudhary, P.; Pandit, V. Development of Buccal Drug Delivery System: Novel Therapy for Diabetic Patients with Hypertension. Indo Global J. Pharm. Sci., 2019; 9(2Suppl.): 129. DOI: http://doi.org/10.35652/IGJPS.2019.92S27.

Indo Global Journal of Pharmaceutical Sciences( ISSN 2249 1023; CODEN- IGJPAI; NLM ID: 101610675) indexed and abstracted in CrossRef (DOI Enabling), UGC CARE Journal List, EMBASE(Elsevier), National Library of Medicine (NLM) Catalog, ResearchGate, Publons, CAS (ACS), Index Copernicus, Google Scholar and many more. For further details, visit http://iglobaljournal.com

This is a special issue as an outcome of 'RAPSCON-2019' sponsored by APTI and organized by Sri Sai College of Pharmacy, Manawala, Amritsar, Punjab, India. Relaxation offered in journal format. 